\title{
PROCESSOS BIOTECNOLÓGICOS NA PRODUÇÃo DE BIOINSETICIDAS
}

Erlon Lopes PEREIRA ${ }^{1}$

Bruna Amaral MARTINS ${ }^{2}$

\begin{abstract}
${ }^{1}$ Departamento de Química. Setor de Engenharia Química. Universidade Federal de Viçosa. Campus: Viçosa-MG. CEP: 36570-900. e-mail: erlon.pereira@ufv.br/erlonlopes@gmail.com
\end{abstract}

${ }^{2}$ Universidade Federal de Viçosa/ Departamento de Química. bruna.a.martins@ufv.br

Recebido em: 05/07/2016 - Aprovado em: 15/09/2016 - Disponibilizado em: 18/12/2016

\begin{abstract}
RESUMO:
O controle de insetos é feito, geralmente, empregando produtos químicos, cujos danos ao ambiente e à saúde humana são preocupantes. O controle biológico por entomopatógenos é uma alternativa eficiente, principalmente dada à alta especificidade, ausência de resistência nos insetos alvos e não acumulam no ambiente. Os principais microrganismos entomopatógenos incluem bactérias (Bacillus thuringiensis, Bacillus sphaericus), fungos (Beauveria bassiana, Metharizium anisopliae) e vírus (Baculovirus). Dentre estes, o mais empregado é o Bacillus thuringiensis, cujo gene responsável pela síntese das toxinas por meio da Engenharia Genética permite obter plantas transgênicas. Com exceção dos vírus, os demais são produzidos em processos fermentativos. A produção industrial é atingida se houver conhecimento de processos de ampliação de escala, fundamentados pela engenharia. Esta revisão teve por objetivo reunir informações gerais sobre tais microrganismos e suas produções em meios de cultivo.

Palavras-chave: Biotecnologia. Inseticidas. Controle biológico. Entomopatógeno. Fermentação.
\end{abstract}

\begin{abstract}
:
Usually, the insect control is done with chemicals, which environmental impacts and human health effects are worrying. The biocontrol by entomopathogenic is an effective alternative, due to the high specificity, absence of resistance in target insects and because it do not accumulate in the environment. The main entomopathogenic microorganisms include bacteria (Bacillus thuringiensis, Bacillus sphaericus), fungi (Beauveria bassiana, Metarhizium Metharizium) and virus (baculovirus). Among these, the most used is Bacillus thuringiensis, whose gene is responsible for the synthesis of toxins through genetic engineering that results in transgenic plants. With the exception of viruses, the others are produced in fermentative processes. Industrial production is reached if there is knowledge of range expansion process, based on engineering. This paper aims to review the literature about the subject and to reunite the general information about such microorganisms and their production in culture media.
\end{abstract}

Keywords: Biotechnology. Insecticide. Biological control. Entomopathogenic. Fermentation.

\section{INTRODUÇÃO}

Os insetos que causam danos ao ser

humano devido às perdas econômicas na

geralmente, por produtos químicos, pecuária e na agricultura ou promovendo constituídos, em sua maioria de vetores de doenças (malária, dengue, febre amarela, doença de Chagas) são um organoclorados (como DDT, Endri, etc.) e organofosforados (monocrotofos, paration metílico, etc), cujos efeitos cumulativos problema. O controle destes é realizado, levam a grandes prejuízos ambientais e à 
saúde humana, bem como a rápida seleção de insetos resistentes. Esses produtos químicos problemáticos são denominados de inseticidas. Sua função diversificada vem estimulando a produção de defensivos agrícolas e seu uso indiscriminado mostra-se como um problema para o agronegócio e de saúde pública (ALMEIDA e BATISTA FILHO, 2001; ÂNGELO et al, 2010; THOMAZONI et al., 2014).

Almeida e Batista Filho (2001) descrevem que nesse ano o mercado mundial de defensivos agrícolas atingiu US\$ 1,8 bilhões, sendo os inseticidas e os acaricidas responsáveis por $30 \%$ do total. E de acordo com dados consolidados do Sindicato Nacional da Indústria de Produtos para Defesa Vegetal (SINDIVEG), no ano de 2012 foram vendidos no Brasil 823 mil toneladas de agrotóxicos, o que movimentou um valor de US\$ 9,7 bilhões. Todavia, devido aos problemas ambientais e de saúde publica provocados pela sua utilização, o novo panorama industrial vem buscando alternativas que substituam, de forma eficiente, tal defensivo.

De acordo com Ângelo et al. (2010) o controle por entomopatógenos, também conhecidos como bioinseticidas, é uma alternativa eficiente a substituição dos inseticidas. Os bioinseticidas (BI) possuem alta especificidade, ausência de resistência nos insetos alvos, requerem um número menor de aplicações o que junto com sua composição natural promovem impacto ambiental nulo ou insignificante. Porém, demandam estudos mais aprofundados no isolamento de novos microrganismos, testes de seleção de isolados, processos eficientes de produção e formulação do produto.

Almeida et al. (2001) afirma que os bioinseticidas participavam apenas com $1 \%$ do montante do mercado de defensivo agrícolas. Já Brar et al. (2006), apresenta um valor corresponde a cerca de 5\% do mercado mundial de pesticidas, evidenciando assim que o uso destes produtos vem crescendo. De acordo com Ângelo et al., (2010) as possíveis causas do crescimento de $4 \%$ de 2001 a 2006 foram os elevados custos de produção, ao caráter específico, o que para a preservação do meio ambiente é uma grande vantagem. Já para o agricultor pode ser um sério problema, devido à necessidade da utilização de outros produtos contra as pragas não controladas pelos BI e a baixa persistência do efeito larvicida quando aplicados em campo (FISCHER, 2014).

Segundo Angelo et al. (2010) a aplicação de BI requer grandes quantidades do agente ativo. Capalbo et al. (2001) descreve que no processo de produção do BI priorizava-se o desenvolvimento em meio artificial (in vitro) que garantia a produção em larga escala. De acordo com os autores agente biológico vírus, bactérias e fungos podem ser 
utilizados para produção dos BI. Os autores mencionam como dificuldade o BI viral visto que vírus tinham que ser produzidos em células animais viáveis, já os fungos e bactérias poderiam ser produzidos em processos fermentativos. Atualmente, Gusmão (2013) explica que a para produzir BI em escala industrial deve-se utilizar processos fermentativos, os quais facilitam a produção e estocagem do BI o que se priorizava até agora a produção com fungos e bactérias. Todavia, Almeida (2010) e Dantas et al. (2014) afirmam que é possível a produção de BI virais através de processos fermentativos sendo esta a nova expectativa para pesquisas posteriores.

De acordo com Dias (1992) as bactérias utilizadas na produção de BI podem além de atuarem como agente biológico na fermentação serem utilizadas como agente fornecedor do gene de modificação para outras bactérias ou vegetais. Os autores descrevem o caso da utilização das bactérias Bacillus thuringiensis (Bt) na produção de BI por meio da engenharia genética onde os genes do Bt foram inseridos em vegetais e bactérias. No primeiro caso, os genes que codificam as proteínas responsáveis pela síntese das toxinas do BI foram inseridos em vegetais modificando sua cadeia genética o que resultou na produção de plantas transgênicas. No segundo caso, a transferência dos genes foi realizada para outras bactérias consideradas de fácil cultivo possibilitando a síntese das toxinas empacotadas. Outros exemplos da utilização de Bt para modificação genética de vegetais tornando-os resistentes a pragas foram estudados por Serafini et al. (2002); Bobrowski et al. (2003); Knaak e Fiuza (2006); Pinto e Fiuza (2008); Zancanaro et al. (2012).

Visto o exposto, a produção de BI utilizando processos fermentativos vem se tornando predominante o que estimula o seu estudo devido sua importância econômica, industrial e ambiental. Este trabalho teve como objetivo apresentar uma revisão sobre os aspectos biotecnológicos que envolvem os processos fermentativos utilizados na produção de BI.

\section{ASPECTOS GERAIS DA PRODUÇÃO DE BI}

Segundo Capalbo et al. (2001) as condições de assepsia durante todo o procedimento devem ser observadas para evitar contaminações por outros microrganismos, todo o equipamento e meios de cultivo devem ser esterilizados em autoclave ou por vapor, de forma a manter as condições de assepsia necessárias, exigidas pelos processos biológicos.

O Quadro 1 mostra informações provenientes do Banco de Microrganismos Entomopatogênicos "Oldemar Cardim Abreu", do Instituto Biológico de Campinas, 
São Paulo sobre os microrganismos que podem ser utilizados para produção de BI e número de representantes dos mesmos.

Quadro 1 - Microrganismos entomopatogênicos

\begin{tabular}{|c|c|}
\hline Microrganismos & $\begin{array}{l}\text { Número de } \\
\text { Isolados }\end{array}$ \\
\hline \multicolumn{2}{|l|}{ Bactérias } \\
\hline Bacillus thuringiensis & 3 \\
\hline Bacillus sphaericus & 2 \\
\hline \multicolumn{2}{|l|}{ Fungos } \\
\hline Arthrobotrys SP. & 1 \\
\hline Aschersonia aleyrodis & 1 \\
\hline Beauveria bassiana & 197 \\
\hline Beauveria broghniartti & 6 \\
\hline Beauveria amorpha & 1 \\
\hline Cladosporium sp. & 3 \\
\hline Cordycipes sp. & 1 \\
\hline Hirsutella thompsonii & 2 \\
\hline Metarhizium anisopliae & 61 \\
\hline Nomuraea rileyi & 9 \\
\hline Isaria fumosoroseus & 21 \\
\hline Isaria farinosus & 15 \\
\hline Isaria lillacinus & 2 \\
\hline Sporothrix insectorum & 7 \\
\hline Verticilium lecanii & 2 \\
\hline \multicolumn{2}{|l|}{ Vírus } \\
\hline Família Baculoviridae & 5 \\
\hline \multicolumn{2}{|l|}{ Nematóides } \\
\hline Steinernema carpocapsae & 8 \\
\hline
\end{tabular}

Fonte: Almeida e Batista Filho (2001).

O Quadro 1 mostra o potencial biológico das variedades de microrganismos que atuam como BI, tais com bactérias, fungos, vírus e nematelmintos. Pode se observar que os fungos apresentam o maior número de representante, contudo as bactérias dominam o setor de produção de BI., segundo Fischer (2014), o Bacillus thuringiensis é responsável por mais de $90 \%$ dos bioinseticidas disponíveis no mercado internacional, mesmo tendo um custo superior ao do Baculovírus.

Silva et al. (2012) utiliza isolados provenientes do banco de microrganismos Oldemar Cardim Abreu em seus bioensaios com o objetivo de avaliar e comparar a eficiência dos fungos $S$. insectorum, $M$. anisopliae, Isaria fumosorosea, Isaria farinosa e $S$. insectorum no controle de Leptopharsa heveae. Isso mostra que o referido banco citado no Quadro 1 possui importância internacional e nacional devido a qualidade dos isolados.

\section{BIOINSETICIDAS BACTERIANOS}

As bactérias formadoras de endósporos apesar de gerarem problemas à indústria de alimentos são importantes agentes biológicos na obtenção de BI. Seus principais representantes pertencem em sua maioria à família Bacillacea, incluindo cinco gêneros: Bacillus, Sporolactobacillus, Clostridium, Desulfotomaculum e Sporosarcina. Dentre os gêneros mencionados apenas Bacillus é capaz de produzir a toxina utilizada na fabricação de BI. Este gênero possui metabolismo facultativo e em termos de quantidade possui o maior número de representantes seguido pelo Clostridium de metabolismo anaeróbio (LIU et al., 1994).

Serafini et al. (2002) caracterizam Bacillus thuringiensis (Bt) como bactéria Gram-positiva, anaeróbia facultativa, 
mesófila, quimioheterotrófica, com forma de bastonetes e o principal agente endopatogênico. Os autores mencionam que em condições adversas esta desenvolve um ciclo de esporulação característico de gênero Bacillus, com endósporo.

Bechtel et. al (1976) apresenta que para
Btum evento adicional, que não ocorre normalmente em outros bacilos, é a formação de um cristal parasporal proteico, que é visível na fase de esporulação. $\mathrm{O}$ endósporo e a formação dos cristais são análogos às fases de esporulação convencionais. $\mathrm{O}$ processo está ilustrado na Figura 1.

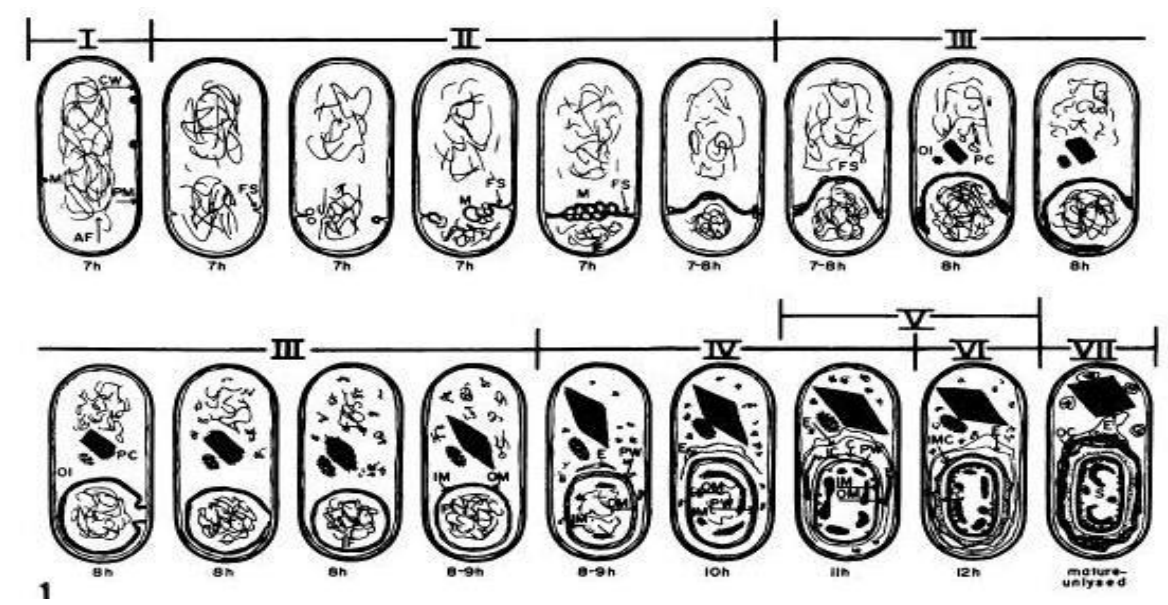

Figura 1. Diagrama esquemático da esporulação em Bacillus thuringiensis.

Fonte: Bechtel et al., (1976).

Legenda: I - formação do filamento axial. II - formação do septo do pré-esporo. III - invaginação da membrana e citoplasma e formação do pré-esporo. IV a VI - formação de exoesporo, parede celular primordial, córtex, capa dos esporos acompanhadas da transformação do nucleóide. VII - maturação de esporos e lise dos esporângios.

O evento apresentado por Bechtel et al. (1976), que se inicia na Fase III (Figura 1) durando até a conclusão da esporulação, é o responsável pela atividade entomopatogênica do Bt. As inclusões cristalinas denominadas delta-endotoxinas ou proteínas Cry constituem o princípio ativo tóxico aos insetos. $\mathrm{O}$ cristal é identificadono compartimento da célula mãe, e segundo Adams et. al (2002), corresponde a aproximadamente $25 \%$ do peso seco da célula. Tais proteínas são codificadas por genes que em geral se localizam em plasmídios e, em menor fração no cromossomo bacteriano.

Os cristais quando ingeridos pelas larvas dos insetos são solubilizados em $\mathrm{pH}$ alcalino, característico do intestino do artrópode, liberando as pró-toxinas que são clivadas por proteases do próprio inseto, resultando em toxinas ativas. Fischer (2014)apresenta a ação das toxinas na paralisia do aparelho digestor, ocasionando morte por inanição e paralisia geral dos 
músculos. Se o endósporo também é ingerido, este pode germinar no interior do inseto ocasionando septicemia ou, potencializando o efeito das toxinas em ação conjunta.

Adams et al. (2002) descreve que durante a fase de esporulação há também a produção Thuringiensia, essa substância é uma $\alpha$ e $\beta$ - exotoxina, caracterizada por ser termoestável e tóxica para alguns insetos e, diferente das endotoxinas esta pode ocasionar efeitos adversos em organismos não alvos. Segundo Ângelo et al., (2010), além desta exotoxina, muitos tipos de $\mathrm{Bt}$ produzem proteínas denominadas Vip (vegetative insecticidal proteins) que são sintetizadas ao longo da Fase vegetativa de crescimento. As proteínas Vip não integram o cristal proteico, mas contribuem para a toxicidade global intensificando a ação das proteínas Cry.

Segundo Almeida et al. (2001) o isolamento de bactérias do gênero Bacillus normalmente é realizado a partir de amostras de solo e de lagartas infectadas, utilizando-se o método de Travers et al.(1987). Neste, emprega-se um tratamento térmico com $\mathrm{pH}$ de 6,8, eliminando grande parte das bactérias não-esporulantes, restando apenas os esporos. Os esporos são então cultivados em meio com extrato de levedura e, posteriormente as bactérias do gênero Bacillus em estado vegetativo são isoladas por métodos de coloração de Gramm ou coloração diferencial. Por fim as bactérias isoladas podem ser armazenadas em tubos de cultura com óleo mineral sob $\pm 10^{\circ} \mathrm{C}$, em galão de nitrogênio ou forma liofilizada.

\subsection{Meio de cultura}

As matérias-primas utilizadas segundo estudo de Dias (1992) diferem um pouco, no caso de B. thuringiensis e de B. sphaericus, uma vez que este último não consome açúcares, sendo aminoácidos e proteínas as suas principais fontes de carbono e nitrogênio. Bt consome açucares e amido, além de aminoácidos e proteínas, sendo assim mais simples a escolha de seus substratos.

A fonte de carbono para cultivo de $\mathrm{Bt}$ varia muito conforme o objetivo da fermentação, bem como da linhagem cultivada. O trabalho de Öskan et al. (2003) revela que a melhor fonte para crescimento vegetativo não corresponde à melhor fonte para esporulação e formação dos cristais, e que glicose amido e melaço tem efeito repressor no na produção de proteínas Cry. E segundo os autores, as melhores fontes de carbono para produção de cristais tóxicos e esporulação são lactose, sacarose, dextrina, aveia, maltose, glicerol e insulina.

$\mathrm{Na}$ obtenção de bioinseticida a partir de Bacillus thuringiensisvar.israelensis (Bti), Ernandes (2004) empregou como meio de cultivo resíduos e subprodutos tais como água de maceração de milho ("milhocina"), um subproduto do processamento industrial do 
milho, ("manipueira"), um subproduto do processamento da farinha de mandioca e sangue bovino oriundo de abatedouros. Foi verificado que a concentração de "manipueira" não influencia tanto no processo, mas foi evidenciada a necessidade de esterilização do meio, e que a adição do sangue bovino também promove maior eficiência.

A otimização realizada por Pessanha (2008) demonstrou o efeito da composição de meios formulados com caldo de cana, extrato de levedura e sulfato de amônio, sendo que elevadas concentrações residuais de sacarose foram observadas nos meios com caldo de cana ou sacarose P.A, indicando baixa capacidade do (Bti) para metabolizar este dissacarídeo.

Rodrigues (2009) avaliou a viabilidade de emprego do xarope residual da desidratação de abacaxi para o cultivo de (Bti), para o controle de Aedes aegypti obtendo um ótimo de substrato açúcares redutores correspondentes a $30 \mathrm{~g} \mathrm{~L}^{-1}$.

Ângelo et al. (2010) apresentam os principais ingredientes utilizados em meios de cultivo de bactérias entomopatogânicas e suas concentrações empregadas no cultivo de Bt na América do Norte. Além disso, mostra também os diversos meios alternativos estudados, tais como: à base de batata, extrato de soja suplementado com cistina, à base de água de coco, águas residuais de indústrias e de estações de tratamento de água, sendo alcançados bons resultados.

As fontes de nitrogênio são tanto orgânicas quanto inorgânicas, e ambas são utilizadas em conjunto. Ângelo et al. (2010) afirmam que não é aconselhável o uso apenas de nitrogênio inorgânicos, pois há diminuição do crescimento e da esporulação em relação ao que emprega ambas as fontes. Entre as fontes orgânicas de nitrogênio, o extrato de levedura é bastante utilizado, assim como peptona e derivados de soja apresentam bons resultados. Alternativamente, destacam-se: farinhas derivadas de proteína animal (farinha de peixe e de crisálida) e alguns cereais (cevada e trigo).

A utilização da cama de frango em meio de cultivo de Btipara controle do vetor da dengue foi estudada por Melo et al. (2011) e o bioinseticida obtido possibilitou uma maior mortalidade de larvas em comparação com os bioinseticidas produzidos com bagaço de mandioca e polpa cítrica.

Segundo Rossi (2012) a glicerina residual da produção de biodiesel (GR) propicia um meio fermentado mais potente do que o mesmo produzido empregando glicerina purificada (GP), demonstrando que a GR é uma fonte de carbono mais viável economicamente. $\mathrm{O}$ autor concluiu que a melhor composição de meio de cultura foi utilizando a concentração de $10 \mathrm{~g} \mathrm{~L}^{-1}$ de GR, $6 \mathrm{~g} \mathrm{~L}^{-1}$ de extrato de levedura, $3 \mathrm{~g} \mathrm{~L}^{-1}$ de 
$\left(\mathrm{NH}_{4}\right)_{2} \mathrm{SO}_{4}, 0,12 \mathrm{~g} \mathrm{~L}^{-1}$ de $\mathrm{CaCl}_{2} \cdot 2 \mathrm{H}_{2} \mathrm{O}, 1,5 \mathrm{~g}$ $\mathrm{L}^{-1}$ de $\mathrm{MgSO}_{4} .72 \mathrm{H}_{2} \mathrm{O}, 0,009 \mathrm{~g} \mathrm{~L}^{-1}$ de $\mathrm{MnSO}_{4}$, $1,5 \mathrm{~g} \mathrm{~L}^{-1}$ de $\mathrm{K}_{2} \mathrm{HPO}_{4}$ e $1,5 \mathrm{~g} \mathrm{~L}^{-1}$ de $\mathrm{KH}_{2} \mathrm{PO}_{4}$ com condição de aeração otimizada em $45 \%$ de oxigênio em relação ao valor de saturação. Esse resultado permitiu produzir um meio fermentado 583 vezes mais potente que utilizando GP nas mesmas condições.

Chagas (2012) além da produção de bioinseticida por $\mathrm{Bt}$ a partir de glicerol proveniente do biodiesel, avaliou o efeito do $\mathrm{pH}$ e do ácido acético no processo. Empregou-se concentrações de $1 \mathrm{~g} \mathrm{~L}^{-1}, 3 \mathrm{~g} \mathrm{~L}^{-1}$ e $5 \mathrm{~g} \mathrm{~L}^{-1}$ de ácido acético, sendo comparada as adições no início, no ponto de menor $\mathrm{pH}$ e no de desaceleração do aumento do pH. E o resultado mais expressivo de produção de toxinas foi obtido com adição de $5 \mathrm{~g} \mathrm{~L}^{-1}$ no início da fermentação.

Gusmão (2013) cita que as matériasprimas mais empregadas como subtrato para o crescimento de Bt são farelo de soja, água de maceração de milho, melaço, farelo de semente de algodão, farelo de feijão, caseína e farinha de peixe. Perini (2014) acrescenta que o leite UHT pode ser utilizado como matéria prima para crescimento de $\mathrm{Bt}$, pois os autores observaram desenvolvimento de bacterias gênero Bacillus spp ao realizar estudos microbiologia preditiva descritos através de modelagem matemática.

Com base no exposto em relação aos meios de cultura, o Bacillus thuringiensis pode ser cultivado em meios de culturas provenientes de diversos tipos de matéria prima. Neste contexto os resíduos agroindustriais com destaque para a glicerina proveniente da produção do biodiesel. Além disso, o B. thuringiensisvar.israelensis é a subespécie mais estudada devido ao problema social de controle da dengue.

\subsection{Processos de fermentação}

Dias (1992) afirma que a produção, tanto de Bt quanto de Bacillus sphaericus (Bs), é bastante simples. Isso porque os substratos passam por pré-tratamentos e são transformados em meios de cultura pela adição de sais minerais. A fermentação deve ser conduzida em temperaturas entre 28 e $32^{\circ} \mathrm{C}$, havendo necessidade, em alguns casos de controle de $\mathrm{pH}$ em torno de 7. O tempo de processo, dependendo das condições pode demorar de 24 a 72 horas, e ocorrem em tanque de 2 a 500 mil litros. Em seguida, o caldo fermentado passa por operações de separação (precipitação, centrifugação, filtração tangencial, ultrafiltração, etc.) e a biomassa concentrada é formulada.

Capalbo et al. (2001) descrevem as etapas da fermentação industrial de $\mathrm{Bt}$ realizada em reatores com controle, monitoramento e registro das condições (temperatura, aeração, e outras) da fermentação submersa descontínua. As etapas preliminares são realizadas em pequenos 
reatores de 1 a 5 litros, seguidas de etapas intermediárias em reatores entre 10 e 20 litros, sendo que as etapas posteriores atingem até 10.000 litros ou mais por reator.

Ângelo et al. (2010) citam que a forma mais comum de produção de $\mathrm{Bt}$, é por fermentação submersa descontínua, processo em batelada, realizada em tanques agitados. $\mathrm{O}$ pré inóculo, geralmente feito em frascos pequenos, pré-fermentador, com $1 / 5$ do volume do fermentador final. Em geral, as proteínas Cry são formadas no fim da fermentação, quando as condições do meio ficam desfavoráveis, e como o produto é retirado apenas ao fim do processo, em que cerca de 6 a $8 \%$ da cultura é de sólidos, e os esporos e cristais chegam a representar $50 \%$ dessa fração. O cultivo de Bt é feito em torno de $30^{\circ} \mathrm{C}$ e o pH constante é comumente empregado, havendo controvérsias dada a variação na faixa de $\mathrm{pH}$ proporcionar melhorias na produção enquanto outros consideram tais variações prejudiciais. Por fim indica que a melhor produção de toxinas se dá com teor de oxigênio em torno de $26 \%$, alcançado com agitação de 300 rpm e aeração de 1 vvm ou 500 rpm e 0.6 vvm, para Btiem um fermentador de 5 litros.

Berbert-Molina (2008) avaliou a
concentração de glicose na cinética de
crescimento de Bti. A concentração inicial de
glicose variou de 10 a $152 \mathrm{gL}^{-1}$. A velocidade
de crescimento específica máxima $\mu$ não foi

afetada até $75 \mathrm{~g} \mathrm{~L}^{-1}$, sendo observada inibição do crescimento e retardo da esporulação para valores superiores. $\mathrm{O}$ valor máximo de rendimento $\mathrm{Y}_{\mathrm{x} / \mathrm{s}}$ obtido foi de $0,83 \mathrm{~g} \mathrm{~g}^{-1}$, para concentração inicial de glicose de $10 \mathrm{~g} \mathrm{~L}^{-1}$.

A cinética de crescimento, esporulação, e toxicidade de Bti foram avaliados por Boniolo et al. (2012) em diferentes concentrações de oxigênio. Realizaram experimentos a $5 \%, 20 \%$ e $50 \%$ de oxigênio dissolvido, sendo obtidos melhor rendimento celular e concentração de biomassa com 50\%, além de maior número de esporos com aumento da atividade tóxica do caldo nove vezes superior à obtida com 5\% (DL ${ }_{50}$ de 39 e $329 \mathrm{mg} \mathrm{L}^{-1}$ ). Subsequentemente, depois de atingida a concentração celular máxima, alterou-se o teor de oxigênio, para 0, 5, 20 e 100\%. A interrupção do fornecimento de oxigênio reduziu fortemente a produção de esporos e a saturação de $100 \%$ favoreceu o aumento da atividade tóxica cerca de quatro vezes ( $\mathrm{DL}_{50}$ de $8,2 \mathrm{mg} \mathrm{L}^{-1}$ ). Com a utilização de oxigênio puro foi obtido $70 \%$ da concentração de biomassa em relação aos ensaios com ar, não há esporulação nem síntese de toxinas.

Segundo Gusmão (2013), a produção de Bt é em sua maioria por fermentação submersa descontínua, sendo que seu crescimento ocorre na faixa ótima de $\mathrm{pH}$ entre 6,5 e 7,5. E a temperatura ideal é entre 26 e $37^{\circ} \mathrm{C}$. E na separação e recuperação das 
toxinas os métodos citados são a

contínua.

centrifugação e micro-filtração, mais comuns, e em desenvolvimento destacam-se a liofilização e a flotação.

Dias (1992) apresenta um estudo muito importante na otimização do processo fermentativo realizado na Argentina, onde foram comparados parâmetros de produção de Btem processo descontínuo e descontínuo alimentado, em que em ambos a toxidade microbiana foi diretamente proporcional à concentração celular. Sendo que o processo descontínuo alimentado mostrou-se mais vantajoso, obtendo-se produtividades celulares e de toxinas cerca de $90 \%$ superiores ao descontínuo.

Segundo Dias (1992) e Moraes et al. (2001) é raro o uso da fermentação contínua para microrganismos esporuláveis. O crescimento em processo contínuo favorece a formação de colônias distintas da colônia mãe, e em condições laboratoriais o processo contínuo com Bt é bem sucedido para sistemas com mais de um estágio, uma vez que variações na velocidade de crescimento e no teor de carboidratos do meio aceleram a esporulação.

Os resultados analisados mostraram que os trabalhos realizados atualmente utilizam o processo descontínuo. $\mathrm{O}$ processo descontinuo alimentado foi avaliado apenas por Dias (1992). Não foram encontrados exemplos de cultivo em fermentação

\subsection{Transgenia}

No final do século XX, a engenharia Genética permitiu a obtenção de produtos biotecnológicos pela inserção de genes de interesses em plantas, englobadas pelas plantas transgênicas. O Bacillus thuringiensis é um importante fornecedor de genes na criação das plantas-Bt, as quais produzem suas próprias proteínas Cry, ficando resistentes e protegidas do ataque de insetos susceptíveis (SERAFINI et al., 2002; BOBROWSKI et al., 2003; CAPALBO et al. 2005).

Contudo, como apresentado por Moraes et al. (2001) e Bobrowski et al. (2003), tal prática possui limitações, dada a dificuldade das células vegetais em produzir o cristal em níveis que rapidamente matem as larvas ou, podendo também expô-las a doses muito altas de toxina, induzindo assim à resistência toxina.

Trata-se de um tema que envolve produção agropecuária e de alimentos, assim a seleção de novos genes responsáveis pela resistência aos insetos é recorrente em pesquisas desenvolvidas por Serafini et al., (2002); Bobrowski et al. (2003);Knaak e Fiuza (2006); Pinto e Fiuza (2008); Zancanaro et al. (2012); Bedin et al. (2015).

\subsection{Toxinas empacotadas}


Em seu estudo, Dias (1992) relata que através da transferência de genes que codificam a endotoxina Bt para Pseudomonas fluorescens, esta passa a produzir o cristal proteico ao final da fase exponencial de crescimento, mas ao contrário do bacilo, não sofre a lise celular, não há a formação de endósporo. Industrialmente, esta característica permite obter a toxina encapsulada, cuja ação aparecerá apenas no intestino das lagartas, onde a alcalinidade e as proteases degradam a parede celular.

Essa estratégia pode ser empregada para outras bactérias receptoras de genes, de modo a obter cápsulas de toxinas específicas para diversos insetos. Sendo dois aspectos relacionados a esta alternativa: a biossegurança e a indução de resistência. Como este bioinseticida não contém nem microrganismos vivos, nem esporos, sua utilização não acarreta problemas de biossegurança. Por outro lado, por conter apenas a toxina como principio ativo, pode levar à resistência pelos insetos, com maior rapidez do que o complexo microrganismoesporo-toxina poderia levar.

\section{BIOINSETICIDAS FÚNGICOS}

Segundo Junges (2010) os principais fungos utilizados para controle de pragas pertencem ao grupo Hypocreales dentre eles o com ciclo de vida mais explorado é o anamórfico, antes chamados de hifomicetos ou fungos mitospóricos. Esses fungos agem por contato sobre seus hospedeiros, os conídios ou esporos são "sementes" do fungo que funcionam como unidades infectivas e constituem o ingrediente ativo dos micoinseticidas.

De acordo com Dalzoto e Uhry (2009) os conídios podem penetrar em qualquer parte da cutícula do inseto, e tal penetração é mediada por enzimas líticas, podendo também ocorrer pelos aparelhos respiratório e digestório. Como exposto por Junges (2010), o biocontrole mais eficiente, por meio do melhoramento genético, é promovido pela seleção de linhagens com expressão aumentada de enzimas hidrolíticas, como as quitanases, que são fundamentais na penetração através do hospedeiro e da superexpressão de toxinas inseticidas na hemolinfa.

Os fungos comumente utilizados em bioinseticidas no Brasil, de acordo com Pacheco (2015), são Bauveria bassiana e Metarhizium anisopliae, sendo comercializados como uma suspensão de esporos e o melhor desempenho dos produtos são dependentes das condições ambientais ótimas.

Segundo Almeida et al. (2001) os fungos, dentre os entomopatogênicos, são os mais fáceis de ser isolados, tanto de insetos, 
quanto de partes de plantas ou do solo. E os procedimentos de isolamento variam com a Ordem do fungo envolvido, já que os fungos apresentam o maior número de representantes entomopatógenos. A seleção de isolados de Beauveria bassiana patogênicos ao bicudo do algodoeiro foi realizada por Silva (2001) em diferentes regiões geográficas brasileiras e o isolado CG138 de B. bassiana destacou-se como um dos mais virulentos.

\subsection{Meio de cultura}

No Brasil, segundo Faria e Magalhães (2001), a produção massal de fungos se dava à base de cereais, os quais fornecem condições nutricionais e físicas necessárias ao crescimento do microrganismo, como arroz cozido como substrato. Após a colonização do arroz pelo microrganismo, a mistura "arroz+fungo" é triturada e comercializada na forma de pó molhavel.

Sene et al. (2010) averiguou a produção de conídios de $M$. anisopliae à base de arroz polido (meio padrão), arroz vermelho, arroz polido suplementado com melaço $(2,5 ; 5$ e 10)\%, e resíduos agroindustriais, tais como: da cervejeira (farelo ou bagaço de cevada) e da fecularia (farelo ou bagaço de mandioca), arroz polido+resíduo de cervejaria (1:1) e arroz polido + resíduo de fecularia (1:1). Dentre os testados, o meio composto por arroz+resíduo de cervejaria foi verificado a mais elevada produção de 11,3 x
$10^{8}$ conídios.g $^{-1}$ de substrato, sem perda na atividade inseticida e com redução em $50 \%$ nos custos de produção do fungo.

A proporção carbono e nitrogênio $(\mathrm{C}: \mathrm{N})$ do meio é um importante fator a ser considerado no desenvolvimento de meios de cultura, sendo sua composição estreitamente relacionada ao custo e qualidade do fungo, sendo que meios ricos em $\mathrm{C}$, mas deficientes em $\mathrm{N}$, tendem a produzir maior quantidade de conídios (LEITE, et al., 2003).

Silva et al. (2012) realizaram o cultivo de isolados de fungos entomomatógenos. As pré-matrizes em placas de Petri foram preparadas com meio de cultura BDA (Ágar, dextrose e batata), a partir destas placas, matrizes foram preparadas contendo arroz como meio de cultura e, canjica de milho como meio de cultura foi empregada na preparação das sacolas.

\subsection{Processos de fermentação}

Em seus experimentos, Sene et al. (2010) utilizaram erlernmeyer de $250 \mathrm{~mL}$ com $30 \mathrm{~g}$ do substrato e umidade de $70 \pm 10 \%$. Os frascos foram inoculados com $0,5 \mathrm{~mL}$ da suspensão de conídios $\left(1 \times 10^{8}\right.$ conídios $\left.\mathrm{mL}^{-1}\right)$ e incubados em BOD $\left(25 \pm 1^{\circ} \mathrm{C}\right.$, fosfatase por 12 horas, num período de 7 dias).

De acordo com Silva et al. (2012) a produção em sacolas é a empregada em escala industrial para tais tipos de fungos. Em suas análises de isolados de fungos 
entomopatogênicos, utilizaram sacos plásticos de polipropileno e como meio de cultura $400 \mathrm{~g}$ canjica de milho e $200 \mathrm{~mL}$ de solução aquosa de ácido cítrico a $0,3 \mathrm{gL}^{-1}$. Após esterilização por 40 minutos a $120^{\circ} \mathrm{C}$ em autoclave, foram inoculadas com $40 \mathrm{~mL}$ da suspensão obtida das matrizes e, mantidas na sala de germinação climatizada a $26 \pm 2{ }^{\circ} \mathrm{C}$ e fotofase de 12 foras por 15 dias.

Mascarin e Quintela (2013) apresentam uma técnica de produção do fungo $M$. anisopliae com todas as etapas e condições para o cultivo de tal fungo. Neste trabalho é fornecido metodologias para o preparo do inoculo inicial, a produção do fungo em arroz, a secagem em estufa elétrica, a extração dos conídios secos, a secagem final e o modo de armazenamento. A produção se dá basicamente por fermentação semi-sólida, em que o fungo coloniza o cereal e são realizadas em sacos plásticos, sob temperatura ambiente de $25^{\circ} \mathrm{C}$, com um tempo de fermentação de 7 a 8 dias, após esse período a viabilidade dos conídios pode ser comprometida, pois sofrem estímulo para germinar.

Thomazoni et al. (2014) realizaram a produção de conídios de $M$. anisopliae e $B$. bassiana em arroz. Para tal, sacos de polipropileno contendo $200 \mathrm{~g}$ de arroz polido e pré-cozido por 3 minutos em água fervente foram autoclavados por 15 minutos a $120^{\circ} \mathrm{C}$. Após o resfriamento, foi realizada a inoculação de $10 \mathrm{~mL}$ da suspensão de conídios. Os sacos foram incubados a $26 \pm 1{ }^{\circ} \mathrm{C}$ e 12 horas de fotofase por sete dias. Posteriormente o seu conteúdo ficou exposto a um fluxo de ar em bandejas de plástico em câmara asséptica por quatro dias, sob temperatura de $25 \pm 1^{\circ} \mathrm{C}$ e 24 horas de fotofase.

A partir do exposto, a fermentação semi-sólida é a mais empregada, sendo o arroz, o cereal predominante na produção de micoinseticidas. As sacolas plásticas são os locais utilizados para germinação e condições ambientais amenas são necessárias a manutenção do cultivo.

Michereff Filho et al. (2007) apresentam um panorama do emprego de micoinseticidas no Brasil e afirmam que, são vendidos tal como são produzidos, não há uma formulação, ou seja, não há adição de substâncias que the assegurem melhorias na eficiência de controle, conservação ao armazenamento ou praticidade de manuseio, que resulte em vantagens em relação do produto bruto. São comercializados como pómolhável ou mistura "arroz+fungo".

\section{BIOINSETICIDAS VIRAIS}

Castro et al. (1999) afirma ser o Baculovírus é o mais estudado dentre os agentes entomopatogênicos virais. Esse vírus é composto por uma fita dupla de DNA e pertence à família Baculoviridae que é 
taxonomicamente dividida em dois gêneros: Nucleopolyhedrovirus e Granulovirus, que diferem pela morfologia do corpo de oclusão.Os nucleopoliedrovírus (NPV) possuem corpos de inclusão poliédrica (PIB), contendo múltiplas partículas virais, enquanto os granulovírus (GV) contêm, em geral, partículas únicas, ocluídas em corpos proteicos de forma ovoide.

Segundo Dantas (2010) a infecção do inseto ocorre por ingestão dos poliedros virais e a penetração ocorre nas células epiteliais do intestino médio. Os nucleocapsídeos são transportados para o núcleo das células, logo após a penetração, liberando o seu DNA e iniciando o processo de replicação viral. Nos estágios finais da infecção na lagarta, ocorre a ruptura das células, seguida da morte do inseto e oclusão de novos vírus. Atua principalmente no controle da lagarta-docartucho do milho Spodoptera frugiperda, que causa danos consideráveis as culturas de milho.

De acordo com Almeida e Batista Filho (2001) o isolamento de vírus da família Baculoviridae, principal representante dos vírus entomatógenos, também é possível a partir de amostras de solo, assim como fungos e bactérias, porém exige mais tempo para a purificação em relação às bactérias e aos fungos e, de insetos suscetíveis a fim de que se possa testar a patogenicidade e obter a replicação, já que são hospedeiros obrigatórios.

Moscardi e Souza (2002) apresenta uma lista os insetos alvo por baculovirus e os respectivos países que utilizam a prática em determinadas culturas. Mostra o caso de sucesso do seu emprego no controle da lagarta da soja. Apresenta ainda, que o emprego de baculovírus é realizado apenas uma única vez durante a safra, contra uma média de duas aplicações com inseticidas químicos, resultando em benefício econômico da ordem de cerca de $\mathrm{R} \$ 10,00$ por alqueire.

\subsection{Produção comercial}

Segundo Alcântara e Martins (2014) a produção de baculovírus é feita in vivo, através de lagartas infectadas no campo. As lagartas passam por um processamento para purificação do vírus em laboratório. Assim, este processo rústico, possui algumas limitações, pois a produção depende da presença das lagartas, ou seja, só pode ser feita durante a época da produção da cultura infectada.

Valicente et al.(2010) fornecem as etapas e condições do processo em grande escala de baculovírus, que envolve basicamente a criação massal do hospedeiro sadio, seguida da infecção do hospedeiro com o agente de controle biológico e coleta e armazenamento do hospedeiro após a morte. 
Primeiramente realiza-se a produção massal do hospedeiro alternativo artificialmente em salas de criações aclimatizadas, em condições assépticas e controladas. A sala de criação do hospedeiro sadio fique separada fisicamente do local onde se faz a infecção, a coleta e o armazenamento do hospedeiro infectado. No caso de contaminação da colônia, esta deve ser reiniciada com lagartas sadias. A temperatura ideal para a criação da lagarta-docartucho é de $25^{\circ} \mathrm{C}$. A umidade relativa do ar deve ser mantida em torno de $70 \pm 10 \%$ para que não haja ressecamento da epiderme dos insetos, e mesmo a proliferação de contaminantes no recinto. Cria-se os adultos (mariposas) em gaiolas sob uma dieta de água, mel e ácido ascórbico (10\%).

A etapa seguinte, de infecção, é realizada no $7^{\circ}$ dia de idade as lagartas, que são submetidas à exposição ao baculovírus, produto comercializado, por 24 a 48 horas, a temperatura do laboratório de incubação também deve permanecer em $25^{\circ} \mathrm{C}$. Lagartas cujo ponto ideal de infecção foi monitorado produzem uma maior quantidade de poliedros/lagarta aumentando o rendimento e diminuindo o custo de produção.

Quando produzido em larga escala, o fator limitante é o rompimento do tegumento após a morte, fazendo com que o líquido interno extravase e dificulte a coleta e armazenamento do material. E alguns isolados conseguem se multiplicam sem liquefazer as larvas, assim as lagartas mortas podem ir para o processamento e formulação, ou serem congeladas em freezer para posterior processamento. As lagartas mortas infectadas com baculovírus permanecem viáveis por mais de 1 ano quando congeladas a $-20^{\circ} \mathrm{C}$.

De acordo com Almeida et al. (2001) a purificação é realizada através da maceração das lagartas mortas, filtragem e centrifugação da suspensão para retirada de resíduos. Afirma ainda que dentre os microrganismos, os vírus são os mais fácies de ser armazenados, podendo-se utilizar uma suspensão aquosa em geladeira $\left( \pm 10^{\circ} \mathrm{C}\right)$.

A produção de baculovírus como $\mathrm{BI}$ de acordo com o exposto acima se dá ainda in vivo, em que lagartas do cartucho do milho são empregadas para replicação do vírus. Havendo o modo de produção por coleta de lagartas em campo e o de criação das lagartas sadias em laboratório para posterior contaminação.

\section{NOVAS PERSPECTIVAS}

Dantas (2010) apresenta perspectivas ao uso de BI virais. Segundo o autor um fator limitante ao emprego de vírus é a impossibilidade (técnica e econômica) de se produzir Baculovírus in vitro, com o emprego de células de insetos em biorreatores de grande porte, sendo que o maior desafio apresentado é a instabilidade genética gerada 
pela passagem seriada em cultivo nas células de insetos.

Almeida (2010) estudou estratégias de produção in vitro de BI viral selvagem e recombinante, realizando os experimentos laboratoriais em batelada e batelada alimentada. No processo produtivo foram empregadas células do inseto Spodoptera frugiperda, e constatou-se que a batelada alimentada permitiu aumento de três vezes na produção de corpos de oclusão (OB) quando comparada à produção em cultivo em batelada $\left(5,3 \times 10^{7}\right.$ e $1,8 \times 10^{7} \mathrm{OBmL}^{-1}$, respectivamente). Já Dantas (2010) avaliou o efeito da adição de colesterol e ecdisona na produção in vitro do baculovírus, também em células de Spodoptera frugiperda, sendo observada uma queda na produção de $\mathrm{OB}$ de 170 para 92 da terceira para a quarta passagem e indicou influência negativa da adição do colesterol e positiva na adição do hormônio.

Duarte (2015) afirma que atualmente as biofábricas que comercializam micoinsetcidas o fazem na forma de conídios aéreos produzidos por método de fermentação semisólida, empregando substratos à base de cereais, tal como exposto na seção 3 de Fungos Entomopatogênicos. $\mathrm{O}$ autor propõe que o cultivo de fungos através da fermentação submersa. A expectativa é que por meio desta seja possível produzir grandes quantidades de blastosporos, fases leveduriformes, microescleródios ou conídios submersos em um curto intervalo de tempo. Além disso, a fermentação submersa requer menor espaço físico e pouca dependência de mão-de-obra em relação ao método de fermentação sólida. Entretanto os resultados desta pesquisa ainda não estão disponíveis.

Silveira (2016) relata estudos desenvolvidos pelo engenheiro agrônomo e entomologista Luís Garrigós Leite sobre a produção de BI por nematelmintos em simbiose com bactérias e prevê a comercialização do produto no Brasil entre 2017 e 2018. Acredita-se que este produto atue por contato no controle dos insetos, sem causar danos a cultura vegetal. O mecanismo de ação do BI se baseia na penetração do nematoide por orifícios presentes no corpo dos insetos e, uma vez dentro do organismo, liberam as bactérias que causam septicemia, matando-os em 48 horas. Os vermes estudados são dos gêneros Steinerma e Heterorhabditis que estabelecem simbiose natural com as bactérias dos gêneros Xenorhabdus e Photorhabdus, respectivamente. $\mathrm{O}$ meio de cultura usado é composto por gema de ovo, óleo vegetal e extrato de levedura. A comercialização produto BI é realizada com os vermes envoltos em diatomita, um pó de origem mineral, capaz de conservar os vermes úmidos e em estado de latência, sendo ativados quando diluídos em água. 


\section{CONCLUSÕES}

Os bioinseticidas constituem uma alternativa aos inseticidas químicos, com menores dados ao meio ambiente e ao consumidor possibilitando o controle de insetos nas lavouras.

Devido às características biológicas, o B. thuringiensis (Bt) destacou-se como a principal bactéria utilizada no controle biológico de insetos. A prática do emprego de plantas trangenicas modificadas com genes de $\mathrm{Bt}$ tem permitido reduzir efetivamente os danos causados por insetos-pragas e, consequentemente, redução do uso de inseticidas químicos, sem causar danos aos inimigos naturais e demais seres presentes no meio ambiente.

Os entomopatógenos independente da origem (bacteriana, fúngica ou viral) demandam de estudos a cerca do melhor modo de produção como seleção do microrganismo ideal, otimização dos processos fermentativos, emprego de matérias primas de baixo valor comercial. Os resíduos agroindustriais que viabilizam os processos já estão sendo avaliados como matérias primas alternativas para produção de BI.

O emprego de fungos e vírus necessita de maior estudo em relação aos processos produtivos, formulação e a quantia aplicada para controle dos insetos em campo. Em especial aos fungos que possuem um grande número de representantes.
Os processos fermentativos envolvidos na produção industrial são predominantemente descontínuos, ou seja, em batelada que propicia melhores condições para que ocorra a esporulação, fase em que se produzem as toxinas. Os processos envolvendo bactérias são em geral submersos, enquanto que na produção dos fungos os meios semi-sólidos se mostram os mais indicados.

O Brasil ainda não é um grande produtor de BI devido ao elevado custo de produção, a concorrência com os inseticidas químicos e a escassez de incentivo ao desenvolvimento de formulações e novos produtos.

A integração do uso de plantas capazes de expressar as toxinas de $\mathrm{Bt}$ e a conscientização do produtor perante o uso de bioinseticidas consiste em um dos principais desafios apresentados para sucesso da alternativa ecologicamente correta.

\section{REFERÊNCIAS}

ADAMS, T. T.; EITENAN, M. A.; HANEL, $B$. M. Solid state fermentation of broiler litter for production of biocontrol agents.Bioresource Technology, New York, v. 82, n. 1, p. 33-41, 2002.

ALCÂNTARA, L. T. A.; MARTINS, L. S. Utilização do Baculovírus como ferramenta biotecnológica para controle biológico de pragas. Brasília, DF: Núcleo interdisciplinar de pesquisa, 2014

\section{ALMEIDA, A. F. Estratégias de Produção}


in vitro de Bioinseticida Viral: Influências do Isolado, da Cinética e do Modo de Operação. Natal:Tese (Doutorado em Engenharia Química). Universidade Federal do Rio Grande do Norte, 2010.

ALMEIDA, J. E. M.; BATISTA FILHO, A. Banco de Microrganismos

Entomopatogênicos. Biotecnologia Ciência $\&$ Desenvolvimento $-\mathrm{n}^{\circ} 20$ - maio/junho, 2001.

ÂNGELO, E. A.; VILAS_BÔAS, G. T.; CASTRO-GÓMEZ, R. J. H. Bacillus thuringiensis: características gerais e fermentação.Londrina:Semina: Ciências Agrárias, v.31, n.4, p.945-958, out./dez. 2010.

BECHTEL, D.B., BULLA, L.A. Jr.Electron Microscope Study of Sporulation and Parasporal Crystal Formation in Bacillus thuringiensis. Journal of bacteriology. v 127, p. $1472-1481,1976$.

BEDIN, F. A.; ASSMANN, E. J.; POLO, L. R. T.; SCHUSTER, I. Eficiência de eventos transgênicos de resistência a insetos em soja e milho. Revista Cultivando o Saber. ISSN 2175-2214. Vol.8-n2,p.201-214, abril a junho, 2015.

BERBERT-MOLINA, M. A.; PRATA, A. M. R.; PESSANHA, L. G.; SILVEIRA, M. M. Kinetics of Bacillus thuringiensis var.israelensis growth on high glucose concentrations. Journal of Industrial Microbiology \& Biotechnology.Vol. 35.Pp 1397-1404, 2008.

BOBROWSKI, V. L.; FIUZA, L. M.; PASQUALI, G.; BODANESEZANETTINI.Genes de Bacillus thuringiensis: uma estratégia para conferir resistência a insetos em plantas. Santa Maria:Ciência Rural, , v.34,n1,p.843-850, setout, 2003.

BONIOLO, F. S.; RODRIGUES, R. C.; PRATA, A. M. R.; LÓPEZ, M. L.;
JACINTO, T.; SILVEIRA, M. M.; BERBERT-MOLINA, M. A. Oxygen supply in Bacillus thuringiensisfermentations: bringing new insights on their impact on sporulation and $\delta$-endotoxin production. Biotechnological Products and process engineering. Vol.94,pp625-636, 2012.

BRAR, S. K.; VERMA, M.; TYAGI, R. D.; VALÉRO J. R.Recent advances in downstream processing and formulations of Bacillus thuringiensis based biopesticides. Process Biochemistry, New York, v. 41, n. 2, p. 323-342, 2006.

CAPALBO, D. M. F.; MORAES, I. O.; ARRUDA, R. O. M.; MORAES, R. O. Aplicação da Engenharia a processos Biotecnológicos: $O$ caso dos Biopesticidas. Cobenge, EMA- 34 a 38, 2001.

CAPALBO, D. M. F.; VILAS-BÔAS, G. T.; ARANTES, O. M. N.; SUZUKI, M. T. Bacillus thuringiensis - Formulações e Plantas Transgênicas. Biotecnologia Ciência \& Desenvolvimento n.34, p.78 a 85janeiro/junho, 2005.

CASTRO, M. E. B.; SOUZA, M. L.; SIHLER, W.; RODRIGUES, J. C. M.; RIBEIRO, B. M. Biologia molecular de baculovírus e seu uso no controle biológico de pragas no Brasil. Pesquisa agropecuária brasileira. Brasília, v.34, n.10, p.1733-1761, out. 1999.

CHAGAS, M. H. R. Efeito do pH e do ácido acético sobre a produção de bioinseticidas por Bacillus thuringiensis a partir de glicerol provenientes da fabricação de biodiesel.Lorena:Dissertação (Mestrado em Ciências)- Escola de Engenharia de Lorena, Universidade de São Paulo, 2012.

DALZOTO, P. R.; UHURY, K. F. Controle biológico de pragas no Brasil por meio de Beauveria bassiana (Bals.) vuill. São Paulo:Biológico, v.71, n.1, p.37-41, jan./jun., 2009. 
DANTAS, G. C. Efeito da adição de colesterol e ecdisona na produção in vitro do Baculovírus spodoptera frugiperda MNPV. Natal:Dissertação (Mestrado em Engenharia Química). Universidade Federal do Rio Grande do Norte, 2010.

DANTAS, G. C.; ALMEIDA, A. F. de; REIS, A. R. A.; SOUZA, G. R. de MACEDO M. L.; PEDRINI, M. R. S.; "DETERMINAÇÃO

DA QUANTIDADE DE INÓCULO VIRAL PARA O PROCESSO DE PRODUÇÃO EM BATELADAALIMENTADA DE BACULOVÍRUS SPODOPTERA", p. 1936-1943 . In: Anais do XX Congresso Brasileiro de Engenharia Química - COBEQ 2014 [= Blucher Chemical Engineering Proceedings, v.1, n.2]. São Paulo: Blucher, 2015.

ISSN 2359-1757, DOI 10.5151/chemengcobeq2014-1345-19742-162179.

DIAS, J. M. C. S. Produção e utilização de bioinseticidas bacterianos. Pesquisa agropecuária brasileira. Brasília, 27, S/N:5976, abr.1992.

DUARTE, V. S. Desenvolvimento de biopesticida a base de fungos por fermentação líquida. Universidade de São Paulo, Piracicaba, 2015. Disponível em: $<$ http://bvs.fapesp.br/pt/bolsas/153695/desenv olvimento-de-biopesticida-a-base-de-fungospor-fermentacao-liquida/ > Acesso em: julho de 2016.

ERNANDES, S. Obtenção de bioinseticida a partir de Bacillus thuringiensis var.israelensis e aplicação de bioensaios em culicídeos. Tese (Doutorado em Biotecnologia). Universidade Estadual Paulita, Araraquara, 2004.

FARIA, M. R.; MAGALHÃES, B. P. Uso de fungos entomopatogênicos no Brasil. Biotecnologia Ciência \& Desenvolvimento n ${ }^{\circ} 22$-setembro/ outubro, 2001.
FISCHER, T. D. Avaliação do inseticida biológico (Bacillus thuringiensis) no manejo de pragas em cultivares de soja (Glycine Max L.) modificadas geneticamente. Ijuí:Universidade Regional do Noroeste do Estado do Rio Grande do Sul, 2014.

GUSMÃO, F. P. Bioinseticida à base de Bacillus thuringiensis.Lorena:Monografia apresentada à Escola de Engenharia de Lorena da Universidade de São Paulo, como requisito para a conclusão do curso de graduação de Engenharia Bioquímica, 2013.

\section{JUNGES, A. Metarhizium anisopliae:} expressão de proteína tóxica de origem vegetal e análise genômica de quitinases.Porto Alegre: Dissertação (Mestrado em Biologia Celular e Molecular)Universidade Federal do Rio Grande do Sul, 2010.

KNAAK, N.; FIUZA, L. M. Genes cry1Ab e cry1Ac de Bacillus thuringiensis. Biotecnologia Ciência \& Desenvolvimento ano IX - n³6- janeiro/junho, 2006.

LEITE, L.G.; BATISTA FILHO, A.; ALMEIDA, J.E.M; ALVES, S.B. (Ed.). Produção de fungos entomopatogênicos. Ribeirão Preto: A.S. Pinto, 2003. 92p.

LIU, W. M.; BAJPAI, R.; BIHARI, V. High density cultivation of sporeformers.Ann. N.Y. Acad. Sci., v.72, p. 310-325, 1994.

MASCARIN, G. M., QUINTELA, E. D. Técnica de produção do Fungo Entomopatogênico Metarhizium anisopliae para Uso em Controle Biológico.Santo Antônio de Goiás: Embrapa Arroz e Feijão, 2013.

MELO, A. L. A.; SANCHUKL, C. E.; WOLCLECHOWSKL, A. L.; THOMAZSOCCOL, V.; SOCOOL, C. R. Utilização da cama de frango em meio de cultivo de Bacillus thuringiensis var. israelensis berliner para o controle de Aedes aegypti 
Linnaeus. Journal of Biotechnology and Biodiversity. Vol.2, n.4, PP. 1-2, Novembro, 2011.

MORAES, I. O.; CAPALBO, D. M. F.; ARRUDA, R. O. M. Produção de bioinseticidas.In: LIMA. U.A.; AQUARONE, E.; BORZANI; W.; SCHMIDELL, W. (Coord.).Biotecnologia industrial: processos fermentativos e enzimáticos. Porto Alegre: Edgar Blücher, v. 3, 2001. p. 245-265.

MICHEREFF FILHO, M.; FARIA, M. R.; WRAIGHT, S. P. Micoinseticidas e micoacaricidas no Brasil: Como estamos?Brasília:Embrapa Recursos Genéticos e Biotecnologia, 2007.

MOSCARDI, F; SOUZA, M. L. Baculovírus para o CONTROLE DE PRAGAS.

Biotecnologia Ciência \& Desenvolvimento $\mathrm{n}^{\circ}$ 24- janeiro/fevereiro, p. 22-29, 2002.

ÖSKAN, M.; DILEK, F. B.; YETIS, U.; ÖZCENGIZ, O. Nutritional and cultural parameters influencing antidpteran deltaendotoxin production. Research in Microbiology, Paris, v. 154, n. 1, p. 49-53, 2003.

\section{PACHECO, J. L. C. Potencial} entomopatogênico de fungos e actinobactérias marinhas no controle de Brevicoryne brassicae (Hemiptera: Aphididae).Curitiba:Dissertação (mestrado em Microbiologia, Parasitologia e Patologia). Universidade Federal do Paraná, 2015.

PERINI, F. O. Avaliação da multiplicação da Bacillus thuringiensis no leite UHT por meio de modelagem matemática $\mathrm{e}$ microbiologia preditiva.Porto Alegre:Universidade Federal do Rio Grande do Sul, 2014.

PESSANHA, L. G. Otimização da composição do meio de cultivo na fermentação de caldo de cana-de açúcar por Bacillus thuringiesnsis var. israelensis. Campo dos Goytacazes:Tese (Mestrado em Biociência e Biotecnologia)- Universidade Estadual do Norte Fluminense Darcy Ribeiro, 2008.

PINTO, L. M. N.; FIUZA, L. M. Genes cry de Bacillus thuringiensis aplicados na engenharia genética de plantas, conferindo resistência a insetos-praga. Neotropical Biology and Conservation. 3(3):159-168, setembro/dezembro, 2008.

RODRIGUES, R. C. Aproveitamento de xarope residual da desidratação osmótica de abacaxi para o cultivo de Bacillus thuringiesnsis var. israelensis. Campo dos Goytacazes:Disertação (Mestrado em Produção vegetal)- Universidade Estadual do Norte Fluminense Darcy Ribeiro, 2009.

ROSSI, A. A. Obtenção de bioinseticida de Bacillus thuringiensis a partir de resíduos da fabricação de biodiesel.Lorena: Tese (Doutorado em Biotecnologia Industrial) Universidade de São Paulo, 2012.

SENE, L.; ALVES, L. F. A.; LOBRIGATTE, M. F. P.; THOMAZONI, D. Produção de Conídios de Metarhizium anisopliae em meio sólido à base de resíduos agroindustriais. São Paulo:Arquivo do Instituto de Biologia, v. 77, n.3, p.449-456, jul./set., 2010.

SERAFINI, L. A.; BARROS, N. M., AZEVEDO, J.L., Biotecnologia: avanços na agricultura e na agroindústria. Caxias do Sul: EDUCS, 2002.

SILVA, C. A. D. Seleção de isolados de Beauveria bassiana patogÊnicos ao bicudodo-algodoeiro. Brasília:Pesquisa

Agropecuária brasileira,v.36, n.2, p.243-247, fevereiro, 2001

SILVA, E. A. R.; BATISTA FILHO, A.; WENZEL, I. M.; FURTADO, E. L.; ALMEIDA, J. E. M. Seleção de isolados de 
fungos entomopatogênicos para o controle de Leptopharsa heveae (hemiptera: heteroptera, tingidae). São Paulo:Arquivo Instituto de Biologia, v.79, n.4, p.549-556, out./dez., 2012.

SILVEIRA, E. Bioinseticida feito de microrganismos - Vermes e bactérias atuando juntos são matérias-primas de produto para uso comercial na lavoura. São Paulo: FAPESP,Ed.243, 2016.

Disponível em:

<http://revistapesquisa.fapesp.br/2016/05/19/ bioinseticida-feito-de-microrganismos/ > Acesso em: junho de 2016.

SINDIVEG -SINDICATO NACIONAL DAS INDÚSTRIAS DE DEFENSIVOS AGRÍCOLAS. Dados de produção e consumo de agrotóxicos. Disponível em: $\langle$ http://sindiveg.org.br/ > . Acesso em: julho de 2016.

THOMAZONI, D.; FORMENTINII, M. A.;
ALVES, L. F. A. Patogenicidade de isolados de fungos entomopatogênicos à Spodoptera frugiperda (Smith) (Lepidoptera:

Noctuidae).Arquivo do Instituto de Biologia., São Paulo, v.81, n.2, p. 126-133, 2014.

TRAVERS R. S, MARTIN P. A. W, REICHELDERFER C.F. Selective isolation of soil Bacillus spp. Appl Environ Microbiol 53: 1263-1266, 1987.

VALICENTE, F. H; TUELHER, E. S; BARROS, E. C. Processo de Produção Comercial de Baculovírus em Grane Escala. Sete Lagoas: 157 Circular Técnica Embrapa Milho e Sorgo, 2010.

ZANCANARO, P. O.; BUCHWEITZ, E. D.; BOIÇA JUNIOR, A. L.; MORO, F. R. Avaliação de tecnologias de refúgio no cultivo de milho transgênico. Pesquisa agropecuária brasileira, Braília, v.47, n.7, p.886-891, julho 2012. 